\begin{tabular}{ccc}
\hline DE & DE GRUYTER & HUNGARIAN JOURNAL OF \\
\hline INDUSTRY AND CHEMISTRY \\
Vol. 45(1) pp. $9-15(2017)$ \\
hjic.mk.uni-pannon.hu \\
Dol: $10.1515 /$ hic-2017-0003
\end{tabular}

\title{
SELECTIVE REMOVAL OF HYDROGEN SULPHIDE FROM INDUSTRIAL GAS MIXTURES USING ZEOLITE NaA
}

\author{
TAMÁS KRISTÓF* \\ Department of Physical Chemistry, Institute of Chemistry, University of Pannonia, Egyetem u. 10., \\ Veszprém, H-8200, HUNGARY
}

\begin{abstract}
Hydrogen sulphide removal from simple gas mixtures using a highly polar zeolite was studied by molecular simulation. The equilibrium adsorption properties of hydrogen sulphide, hydrogen, methane and their mixtures on dehydrated zeolite $\mathrm{NaA}$ were computed by Grand Canonical Monte Carlo simulations. Existing all-atom intermolecular potential models were optimized to reproduce the adsorption isotherms of the pure substances. The adsorption results of the mixture, also confirmed by IAST calculations, showed very high selectivities of hydrogen sulphide to the investigated non-polar gases, predicting an outstanding performance of zeolite NaA in technological applications that target hydrogen sulphide capture.
\end{abstract}

Keywords: Hydrogen sulphide, Zeolite, Selectivity, Gas mixture, Molecular simulation

\section{Introduction}

Hydrogen sulphide is a highly toxic, acidic and corrosive substance. It is present naturally in landfills, natural and biogases, as well as in several synthesis gases. One of its main anthropogenic sources is the processing of crude oil in industrial refineries, where hydrodesulfurization (HDS) of a variety of streams (e.g. engine fuels) produces hydrogen sulphide-containing gas mixtures, which need to be purified. The economic removal of hydrogen sulphide is a long-standing task of the oil and gas industry. Adsorptive separation involves the use of solid substrates with a specific affinity with particular compounds of the mixture. Zeolites have been applied as catalysts in the petrochemical industry for a relatively long time and these materials can also be used for purification/separation purposes. Zeolites are crystalline aluminosilicates consisting of a threedimensional framework of $\mathrm{SiO}_{4}$ and $\mathrm{AlO}_{4}$ tetrahedra of a highly regular porous structure [1]. The typical size of zeolitic micropores is similar to that of many small molecules. In contrast to various other adsorbents, zeolites generally endure high temperatures and pressures well, and can tolerate harsh chemical environments. The $\mathrm{Si} / \mathrm{Al}$ ratio is a key factor in the application of zeolites. Zeolites with lower $\mathrm{Si} / \mathrm{Al}$ ratios are more hydrophilic, whereas high-silica zeolites often possess fewer structural defects. These latter adsorbents are preferred in the separation of non-polar gases.

Zeolite $\mathrm{NaA}$ is a synthetic microporous zeolite which accommodates extraframework $\mathrm{Na}^{+}$ions. It exhibits an especially high affinity with small polar

*Correspondence: kristoft@almos.uni-pannon.hu molecules such as water. The adsorption and separation properties of zeolite $\mathrm{NaA}$ have already been examined in several experimental [2-6] and theoretical/simulation [7-16] works. In our laboratories, the adsorption characteristics of zeolite $\mathrm{NaA}$ and its performance as a drying agent by classical atomistic simulations [10, 1214] were studied, and new intermolecular potential models for this zeolite [12-14] proposed. Our models were optimized for the study of the selective adsorption of water from its mixtures with less polar or non-polar molecules like simple alcohols, carbon monoxide, hydrogen and methane.

In this paper, the selective removal of hydrogen sulphide by zeolite $\mathrm{NaA}$ is investigated. Molecular simulation predictions for mixture adsorption from twoand three-component gas mixtures containing hydrogen sulphide $\left(\mathrm{H}_{2} \mathrm{~S}\right)$, hydrogen $\left(\mathrm{H}_{2}\right)$ and methane $\left(\mathrm{CH}_{4}\right)$ are presented.

\section{Models and simulation details}

Zeolite NaA [17-18] is of LTA framework type, the structure of which belongs to the Fm-3c space group with a lattice parameter of $2.4555 \mathrm{~nm}$. The threedimensional cubic arrangement of its framework atoms is comprised of three kinds of rings with four (4R), six $(6 \mathrm{R})$ or eight $(8 \mathrm{R})$ oxygen atoms. The interconnection of $4 R$ and $6 R$ rings forms nearly spherical cages (sodalite cages) and these cages are linked by oxygen bridges, shaping straight channels of supercages with a maximum diameter of about $1.2 \mathrm{~nm}$. The standard type of zeolite $\mathrm{NaA}$ has a $\mathrm{Si} / \mathrm{Al}$ ratio of 1 .

In the present study, the unit-cell composition of the standard type of zeolite $\mathrm{NaA}$ was chosen: it consists 
Table 1. Lennard-Jones energy $(\varepsilon)$, size parameters $(\sigma)$ and partial charges $(q)$ for the models used in this work ( $d$ is the bond length, $k$ is the Boltzmann constant).

\begin{tabular}{|c|c|c|c|c|}
\hline $\begin{array}{c}\text { interaction } \\
\text { site }\end{array}$ & $\sigma / \mathrm{nm}$ & $\begin{array}{c}(\varepsilon / k) / \\
\mathrm{K}\end{array}$ & $\begin{array}{c}q / \\
\text { electron } \\
\text { charge }\end{array}$ & $\begin{array}{c}\text { position in the } \\
\text { structure/molecule }\end{array}$ \\
\hline $\mathrm{Na}^{+}(\mathrm{NaA})$ & 0.250 & 100 & 0.60 & $\begin{array}{c}\text { random positions in } \\
\text { supercages }\end{array}$ \\
\hline $\mathrm{Si}(\mathrm{NaA})$ & 0.230 & 22.0 & 2.40 & $\begin{array}{c}\text { experimental atomic } \\
\text { positions [17] }\end{array}$ \\
\hline $\mathrm{Al}(\mathrm{NaA})$ & 0.240 & 16.5 & 1.80 & $\begin{array}{c}\text { experimental atomic } \\
\text { positions [17] }\end{array}$ \\
\hline $\mathrm{O}(\mathrm{NaA})$ & 0.330 & 190 & -1.20 & $\begin{array}{c}\text { experimental atomic } \\
\text { positions [17] }\end{array}$ \\
\hline \hline $\mathrm{S}\left(\mathrm{H}_{2} \mathrm{~S}\right)$ & 0.360 & 122 & - & $d_{\mathrm{S}-\mathrm{H}}=0.134 \mathrm{~nm}$ \\
\hline $\mathrm{H}\left(\mathrm{H}_{2} \mathrm{~S}\right)$ & 0.250 & 50.0 & 0.21 & $\mathrm{H}-\mathrm{S}-\mathrm{H}$ angle: $92^{\circ}$ \\
\hline $\mathrm{X}_{\mathrm{S}}\left(\mathrm{H}_{2} \mathrm{~S}\right)^{*}$ & - & - & -0.42 & $d_{\mathrm{S}-\mathrm{X}}=0.03 \mathrm{~nm}$ \\
\hline \hline $\mathrm{C}\left(\mathrm{CH}_{4}\right)$ & 0.350 & 33.21 & -0.24 & $d_{\mathrm{C}-\mathrm{H}}=0.109 \mathrm{~nm}$ \\
\hline${\mathrm{H}\left(\mathrm{CH}_{4}\right)}^{*} 0.250$ & 15.1 & 0.06 & $\mathrm{H}-\mathrm{C}-\mathrm{H}$ angle: $109.47^{\circ}$ \\
\hline \hline $\mathrm{H}\left(\mathrm{H}_{2}\right)$ & 0.250 & 15.1 & 0.4829 & $d_{\mathrm{H}-\mathrm{H}}=0.0741 \mathrm{~nm}$ \\
\hline $\begin{array}{c}\text { centre of } \\
\text { mass }\left(\mathrm{H}_{2}\right)\end{array}$ & - & - & -0.9658 & $\begin{array}{c}\text { geometric centre of the } \\
\text { linear } \mathrm{H}_{2} \text { molecule }\end{array}$ \\
\hline
\end{tabular}

"off-atom site on the $\mathrm{H}-\mathrm{S}-\mathrm{H}$ angle bisector towards the hydrogen atoms

of 576 framework atoms, namely 96 silicon, 96 aluminium and 384 oxygen atoms. The framework atoms were fixed at the atomic positions measured in $\mathrm{X}$ ray diffraction experiments [17] and the 96 nonframework $\mathrm{Na}^{+}$ions were allowed to move. According to the Löwenstein rule that prohibits $\mathrm{Al}-\mathrm{O}-\mathrm{Al}$ linkages, each $\mathrm{AlO}_{4}$ tetrahedron of this framework is connected to a $\mathrm{SiO}_{4}$ tetrahedron.

Realistic and rigid all-atom intermolecular potential models, consisting of Lennard-Jones and Coulombic interaction sites, were used in the simulations. In these models, the interaction sites were fixed at their experimental atomic positions and assigned their Lennard-Jones energy $(\varepsilon)$ and size $(\sigma)$ parameters, as well as point charges $(q)$. For zeolite $\mathrm{NaA}$, the model that was developed earlier was modified slightly [14] by adding weak Lennard-Jones interaction sites with realistic size parameters $[16,19]$ to the (originally) pure Coulombic silicon and aluminium atoms, thus preserving the dominant role of oxygen atoms in the dispersion interactions of the framework. For hydrogen sulphide, a rigid four-site model proposed recently by Shah et al. [20] was adopted, in which the location of the charge parameter of the sulphur atom is offset on the $\mathrm{H}-\mathrm{S}-\mathrm{H}$ angle bisector towards the hydrogen atoms. An OPLS-AA model [21] was used for the methane molecules, and its Lennard-Jones $\mathrm{H}$ parameters were also applied to the $\mathrm{H}_{2}$ molecules, with partial charges on the atomic sites and on the molecular centre of mass [22]. Table 1 lists the potential parameters of the above models. Instead of the generally accepted Lorentz-Berthelot combining rule, the unlike Lennard-Jones interactions were computed by the combining rule proposed by Waldman and Hagler [23]. This combining rule links the behaviour of the unlike energy parameter $\varepsilon_{i j}$ to the relative sizes of atoms $i$ and $j$ and yields somewhat smaller values for the parameters $\varepsilon_{i j}$ and $\sigma_{i j}$ when $\sigma_{i i} \neq \sigma_{i j}$. Song et al. [24] found that the experimental thermodynamic properties of pure methane can be reproduced more accurately using the Waldman-Hagler combining rule.

Gas adsorption simulations were carried out by the standard grand canonical Monte Carlo methodology [25]. Total pressure $p$ and partial pressures in the gas phase were specified by the chemical potentials of the components; in a diluted gas, these can be calculated from the ideal gas law [12]. The long-range Coulomb interactions were treated with the Wolf method [26-27] using a convergence parameter of $\alpha=2 / r_{c}$ and cutoff radius of $r_{c}=L / 2$ ( $L$ is the length of the simulation box). The simulations involved an equilibration period of $5 \times 10^{7}$ Monte Carlo moves and an averaging period of $2 \times 10^{8}$ moves, consisting of $70 \%$ molecular insertion/deletion and $30 \%$ molecular translation steps. Since the random insertion of molecules is unable to take into account the inaccessibility of the sodalite cages by multiatomic molecules (the physical diffusion pathways to them), creation of $\mathrm{H}_{2} \mathrm{~S}$ and $\mathrm{CH}_{4}$ molecules inside these cages was blocked artificially by placing repulsive dummy atoms at the centres of the cages. As $\mathrm{H}_{2}$ molecules are sufficiently small to pass through the windows of the sodalite cages, the insertion of $\mathrm{H}_{2}$ molecules into these cages was permitted. In either case, the transition of molecules into sodalite cages via translational trial moves was not artificially prevented.

In addition to the adsorption loading, the isosteric heat of adsorption was calculated using the equation:

$$
q=\left(\frac{\partial H^{b}}{\partial n^{b}}\right)_{p, T}-\left(\frac{\partial U^{a}}{\partial n^{a}}\right)_{V, T}
$$

where $H^{b}$ and $U^{a}$ stand for the residual enthalpy and residual internal energy, respectively, $n$ is the number of moles of the substance in the adsorbed $(a)$ or bulk $(b)$ phases. In the grand canonical ensemble, the second part of the equation can be determined from the particle number fluctuations of the simulation and the crosscorrelation of potential energy and particle number fluctuations [28-29]. Assuming the ideal gas adsorbates, the first part of the equation is equal to $R T$, where $R$ is the gas constant and $T$ is the temperature.

Predictions for mixture adsorption were also made using the ideal adsorbed solution theory (IAST) [30-31], which is an analogue of the ideal Raoult's Law. Using IAST, mixture adsorption loadings at a given $T$ can be obtained from single-component adsorption loadings by determining the bulk pressure of each component $p^{\circ}$ at the same spreading pressure $\pi$ of the adsorbed phase:

$$
y_{i}^{a}=p y_{i}^{b} / p_{i}^{\mathrm{o}}(\pi)
$$



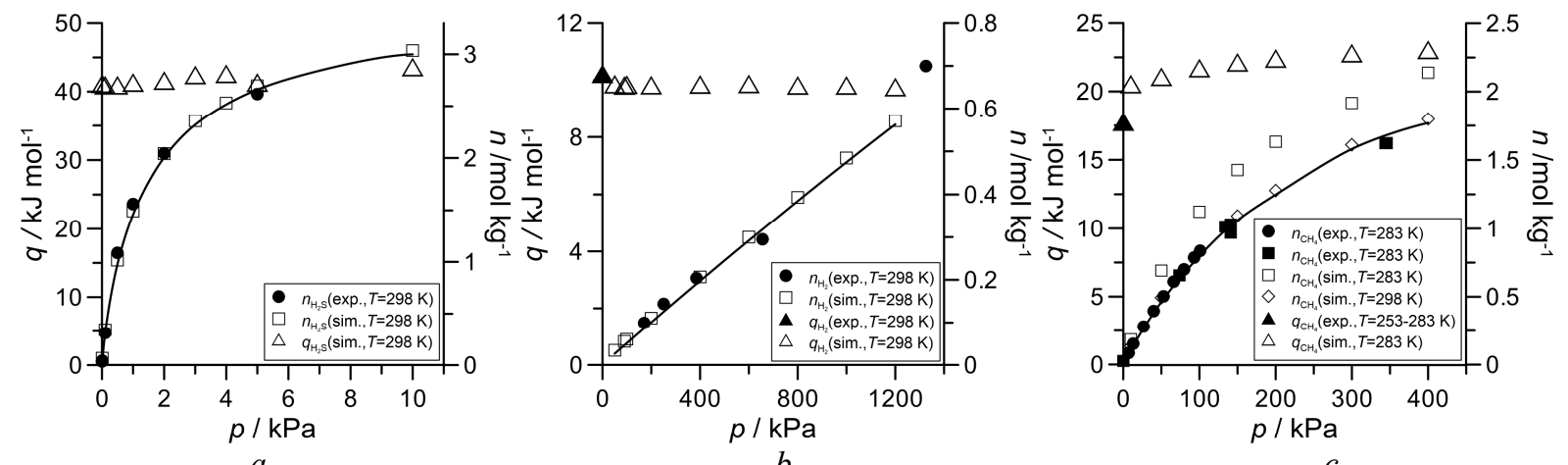

$a$

$b$

c

Figure 1. Equilibrium adsorption loading $(n)$ and isosteric heat of adsorption $(q)$ as a function of the bulk-gas pressure for pure hydrogen sulphide $(a)$, hydrogen $(b)$ and methane $(c)$ on zeolite NaA at the temperatures indicated. The statistical uncertainties of the simulations results do not exceed the size of the symbols. The lines connecting simulation data at $298 \mathrm{~K}$ are only drawn to guide the eyes.

sim.: simulation data; exp.: experimental data.

Here, $y_{i}$ is the mole fraction of component $i$, and $p_{i}^{o}(\pi)$ is given implicitly by:

$$
\pi\left(p_{i}^{\mathrm{o}}\right)=\frac{R T}{A} \int_{0}^{p_{i}^{\mathrm{o}}} n_{i}^{a}(p) d \ln p,
$$

where $A$ is the surface area of the adsorbent.

\section{Results and discussion}

The intermolecular potential models were tested by determining equilibrium adsorption isotherms for pure $\mathrm{H}_{2} \mathrm{~S}, \mathrm{H}_{2}$ and $\mathrm{CH}_{4}$ on zeolite NaA. Experimental data at $298 \mathrm{~K}$ are available for $\mathrm{H}_{2} \mathrm{~S}$ [32] and $\mathrm{H}_{2}$ [8] and nearly room-temperature $(T=283 \mathrm{~K})$ data for $\mathrm{CH}_{4}$ were taken from [33]. Fig. 1 shows that the models are largely able to reproduce the experimental adsorption data for these substances. The reproduction of the experimental isotherm is quite good for $\mathrm{H}_{2} \mathrm{~S}$ and $\mathrm{H}_{2}$. In the case of $\mathrm{CH}_{4}$, the extent of overestimation of the experimental results at $283 \mathrm{~K}$ is considered acceptable, given that the availability of transferable zeolite models that are appropriate as far as adsorption predictions are concerned for both polar and non-polar compounds is rather limited [16]. Furthermore, it is expected that the observed discrepancies between simulation and experimental results for this non-polar component are unable to cause significant errors in terms of mixture adsorption data, where the $\mathrm{CH}_{4}$ content of the gas phase is low and the adsorption of $\mathrm{H}_{2} \mathrm{~S}$ is dominant.

The calculated isosteric heat of adsorption data together with available experimental results for $\mathrm{H}_{2}$ and $\mathrm{CH}_{4}$ [5] are also plotted in Fig.1. The pressuredependence of these data is weak. The general order of $q_{\mathrm{H}_{2} \mathrm{~S}}>q_{\mathrm{CH}_{4}}>q_{\mathrm{H}_{2}}$ is in line with expectations, bearing in mind that the isosteric heat of adsorption at low loadings proves the strength of interaction between the zeolite framework and the adsorbate molecules. $q$ values are considerably higher for polar $\mathrm{H}_{2} \mathrm{~S}$ than for non-polar substances and the order of magnitude of the former indicates the significance of electrostatic interactions. The relation of $q_{\mathrm{CH}_{4}}>q_{\mathrm{H}_{2}}$ can be attributed to the greater polarizability of $\mathrm{CH}_{4}$ molecules (this is implicitly included in the attracting Lennard-Jones terms of the potential model), and to that the explicitly modelled real quadrupole moment of $\mathrm{H}_{2}$ molecules is very weak. Considering the greater uncertainties of these simulation results and that the experimental data for $\mathrm{H}_{2}$ and $\mathrm{CH}_{4}$ were obtained for zero coverage within a given temperature range, these simulation results also confirm the suitability of the models used in this study.

Equilibrium adsorption selectivities were predicted for typical hydrodesulfurization stream outlets of petroleum refinery units separated by zeolite $\mathrm{NaA}$ at near-atmospheric pressures. The studied gas streams were comprised of between 1 and $2 \% \mathrm{H}_{2} \mathrm{~S}$ and $~ 95 \%$ $\mathrm{H}_{2}$; the remaining hydrocarbon content (low alkanes) was represented by the presence of $\mathrm{CH}_{4}$ in the model mixtures. For comparison, other compositions including very low and reasonably high $\mathrm{H}_{2} \mathrm{~S}$ contents, as well as low pressure ranges were also investigated. The raw simulation results for the $\mathrm{H}_{2} \mathrm{~S}-\mathrm{H}_{2}$ mixtures in comparison with IAST predictions shown in Fig.2 illustrate well the dissimilar levels of adsorption of the two substances, with the exception of the nearly zero $\mathrm{H}_{2} \mathrm{~S}$ contents of the bulk mixture. The IAST calculations underestimate the simulation results for $\mathrm{H}_{2}$ at higher pressures and on the whole overestimate the simulation results for $\mathrm{H}_{2} \mathrm{~S}$ at lower pressures (for visual reasons, data obtained within the very low pressure range are not presented in this figure). The most accurate estimations were achieved at $10 \mathrm{kPa}$, which is an impractical parameter for the present applications. Strictly speaking, the hypothesis of IAST which states that the different adsorbate molecules have access to the same adsorbent surface cannot be applied to microporous adsorbents such as zeolite $\mathrm{NaA}$, where the accessible surface area depends on the size of the adsorbate. In light of this, the IAST predictions can be considered to be remarkably accurate. 


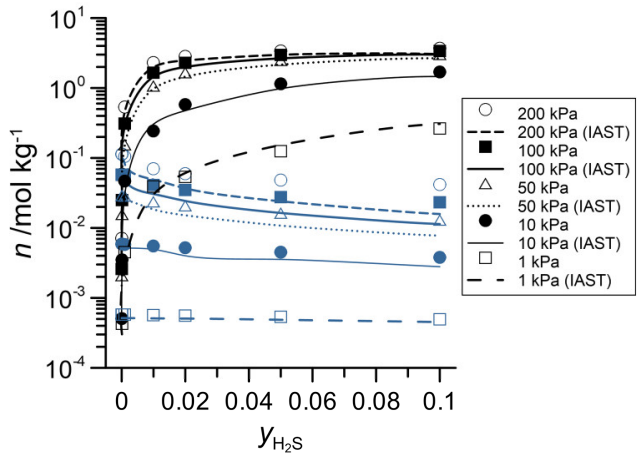

Figure 2. Comparison of the IAST predictions with simulation data for hydrogen sulphide (black) and hydrogen (blue). Equilibrium adsorption loading $(n)$ as a function of the mole fraction of hydrogen sulphide $\left(y_{\mathrm{H}_{2} \mathrm{~S}} \mathrm{~S}\right.$ in the binary gas phase mixture on zeolite $\mathrm{NaA}$ at $298 \mathrm{~K}$ and at the pressures indicated. The statistical uncertainties of the simulation results do not exceed the size of the symbols. (For interpretation of the references to colour in this figure, the reader is advised to refer to the online version of this article.)

The calculated equilibrium selectivities are defined as:

$$
S=\frac{n_{\mathrm{H}_{2} \mathrm{~S}}^{a} / n_{j}^{a}}{n_{\mathrm{H}_{2} \mathrm{~S}}^{b} / n_{j}^{b}},
$$

where $n_{j}$ stands for the equilibrium number of moles of $\mathrm{H}_{2}$ in the investigated two-component mixtures or the sum of the equilibrium numbers of moles of $\mathrm{H}_{2}$ and $\mathrm{CH}_{4}$ in the three-component mixtures, as plotted in Fig.3. On the whole, this zeolite exhibits an exceptional level of selectivity of $\mathrm{H}_{2} \mathrm{~S}$ to the other substances; this is not surprising given the significant differences between the equilibrium adsorption loadings of the pure components (cf. Fig.1). In the case of the two-component gas mixtures, the tendency of the data satisfies the criterion that at the low-pressure limit the selectivity as defined here should be independent of the composition of the bulk-gas mixture (it is the quotient of the ratio of the single-particle partition function of the two substances in the adsorbed phase and the ratio of their free-particle partition functions [34-35]). Because of technical reasons, at lower pressures the uncertainties of the selectivity data are relatively large as these data are calculated from simulation results at very low zeolite loadings. At higher pressures the separation efficiency of this zeolite is somewhat weaker. This and the fact that the change with pressure is less intense at lower $\mathrm{H}_{2} \mathrm{~S}$ contents suggest the existence of a 'crowding' effect, which inhibits more strongly the sorption of the larger molecule, $\mathrm{H}_{2} \mathrm{~S}$. In the case of the investigated three-component mixtures, the overall picture is similar, but the selectivity values are smaller. This makes sense since the competitive effect of the additional component, $\mathrm{CH}_{4}$, for the adsorption sites is stronger. Yet, the values far in excess of 1000 obtained for the

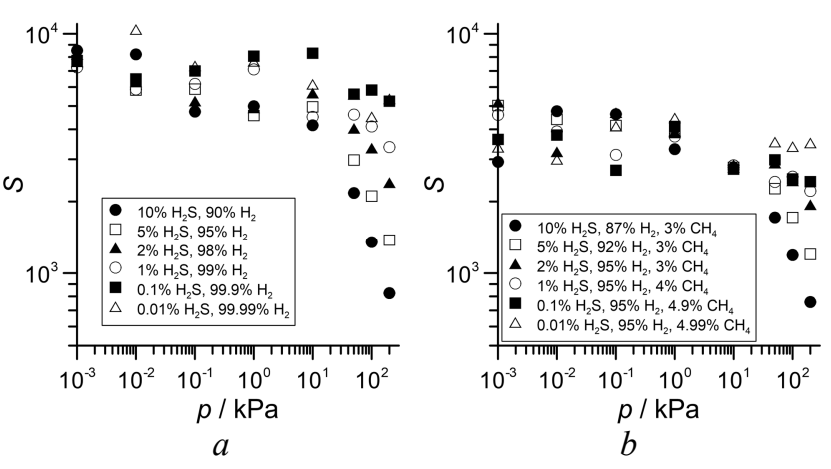

Figure 3. Equilibrium adsorption selectivity $(S)$ on zeolite $\mathrm{NaA}$ at $298 \mathrm{~K}$ as a function of the bulk-gas pressure for binary (a) and ternary $(b)$ gas mixtures with the compositions indicated.

typical hydrodesulfurization streams $\left(1-2 \% \quad \mathrm{H}_{2} \mathrm{~S}\right.$ and $\sim 95 \% \mathrm{H}_{2}$ ) are compelling.

From the mixture adsorption data, once again it was verified that electrostatic effects control the adsorbent-adsorbate interactions with this zeolite, which implies that the amount of adsorption of pure $\mathrm{H}_{2}$ and $\mathrm{CH}_{4}$ should always be small. Adsorbed mole number data showed that the presence of the non-polar components does not affect the sorption of $\mathrm{H}_{2} \mathrm{~S}$ in the adsorbed phase. This conclusion is also supported by the heat of adsorption data (not presented) calculated by assuming one-component mixtures (i.e. using Eq.(1)). These data turned out to be simply the amount-weighted average of the $q$ values of pure components and are very close to $q_{\mathrm{H}_{2} \mathrm{~S}}$ at the given pressure. On the other hand, the degree of adsorption of the non-polar substances is reduced by the presence of $\mathrm{H}_{2} \mathrm{~S}$. Selectivities under real conditions (at 50, 100 and $200 \mathrm{kPa}$ and with realistic $\mathrm{H}_{2} \mathrm{~S}$ contents; 1, 2 and 5\%) shown in Fig. 4 make this fact obvious. Here, $S$ values obtained from mixture adsorption simulations significantly exceed their counterparts calculated for an ideal case of independent adsorption (i.e. by substituting into Eq.(4) the purecomponent adsorption loadings determined at pressures that are equal to the partial pressures of the mixture components). Extensive non-ideality in the adsorbed phase can also be seen from the comparative failure of IAST (which utilizes the assumption that the adsorbed mixture is an ideal solution) to predict the simulation results accurately at near-atmospheric pressures.

It is remarkable that the selectivity of $\mathrm{H}_{2} \mathrm{~S}$ to the two non-polar substances decreases as the temperature and partial pressure of $\mathrm{H}_{2} \mathrm{~S}$ in the bulk gas increase. As the adsorption loading of the zeolite rises, steric hindrance plays an increasingly important role, and sorption of the larger $\mathrm{H}_{2} \mathrm{~S}$ molecules reduces to a greater extent. The impact of an increase in temperature is as expected, e.g. from the higher $q_{\mathrm{H}_{2} \mathrm{~S}}$ values, but the magnitude of decrease in selectivity with temperature changes significantly as a function of the partial pressure of $\mathrm{H}_{2} \mathrm{~S}$. Data lines at the two investigated temperatures seem to converge to similar values at higher partial pressures, because the drop in the sorption of $\mathrm{H}_{2} \mathrm{~S}$ as the temperature increases already becomes 

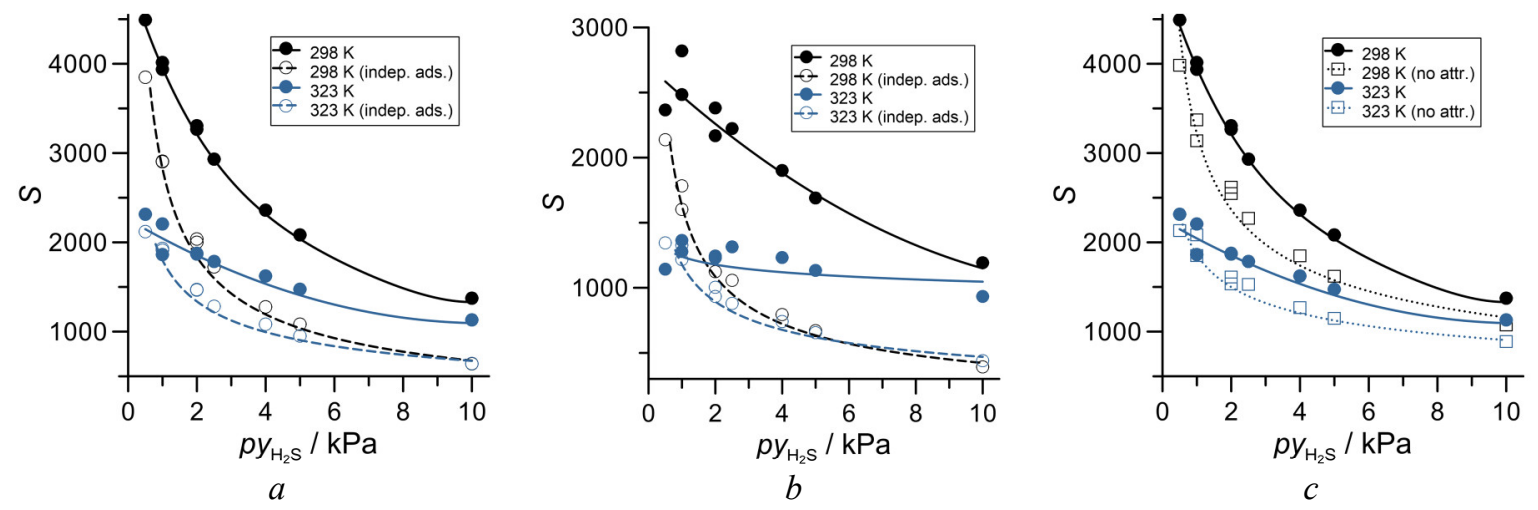

Figure 4. Equilibrium adsorption selectivity $(S)$ as a function of the partial pressure of hydrogen sulphide in the bulk gas for selected binary $(a)$ and ternary $(b)$ gas mixtures on zeolite $\mathrm{NaA}$ at $298 \mathrm{~K}$ and $323 \mathrm{~K}$, and at bulk gas pressures of 50 $\mathrm{kPa}, 100 \mathrm{kPa}$, and $200 \mathrm{kPa}$. Comparison of the mixture selectivity data with the selectivity data for independent adsorption (indep. ads.; panels $a, b$ ) and with mixture selectivity data calculated without adsorbate-adsorbate attractions (no attr., panel $c$ ). (For interpretation of the references to colour in this figure, the reader is referred to the web version of the article.)

less significant at higher loadings. The two panels of Fig.4 also illustrate the above-mentioned difference between the data of the binary $(a)$ and ternary $(b)$ mixtures, i.e. the numerical values are smaller for the ternary mixtures. Besides this, the scatter of the points is larger in panel $b$, because the ratio of $n_{\mathrm{H}_{2}}$ to $n_{\mathrm{CH}_{4}}$ in the bulk gas unavoidably changes as the partial pressure of $\mathrm{H}_{2} \mathrm{~S}$ increases (for compositions, see Fig.3). Finally, panel $c$ in Fig.4 illustrates the influence of adsorbateadsorbate attraction on the adsorption characteristics. It was simulated by eliminating the Coulomb potential and the attractive part of the Lennard-Jones potential, but retaining its soft-sphere repulsion potential component, when calculating the instantaneous adsorbate-adsorbate pair interactions in the adsorbed phase. The observed reduction in $n_{\mathrm{H}_{2} \mathrm{~S}}$ and selectivity is sizable enough to establish that like-like attraction is an important factor in the adsorption of $\mathrm{H}_{2} \mathrm{~S}$.

\section{Conclusion}

In this work, molecular simulation predictions for the adsorption of $\mathrm{H}_{2} \mathrm{~S}$ from simple non-polar gas mixtures of technological interest (hydrodesulfurization stream outlets in petroleum refinery units) on zeolite $\mathrm{NaA}$ were presented. The realistic all-atom intermolecular potential models adopted for the computations were validated by comparing the calculated isotherms of the pure substances with available experimental adsorption data. What is especially noticeable here is the matching of the experimental and simulated adsorption loadings for $\mathrm{H}_{2} \mathrm{~S}$ that was achieved. The investigated zeolite exhibited a remarkable ability to capture $\mathrm{H}_{2} \mathrm{~S}$, from either binary or ternary mixtures with non-polar gases, namely $\mathrm{H}_{2}$ and $\mathrm{CH}_{4}$. The interactions between the polar $\mathrm{H}_{2} \mathrm{~S}$ molecules and the hydrophilic zeolite framework were found to be particularly favourable, and the mixture-adsorption loadings for $\mathrm{H}_{2} \mathrm{~S}$ essentially agreed with the corresponding pure component loadings (with the exception of the very low $\mathrm{H}_{2} \mathrm{~S}$ contents of the bulk- gas mixture). The reverse is true when considering the adsorption of the non-polar gaseous components under technological conditions (at near-atmospheric pressures and with a small proportion of $\mathrm{H}_{2} \mathrm{~S}$ in the bulk); their bindings to the inner surface sites of the zeolite were suppressed by $\mathrm{H}_{2} \mathrm{~S}$. These results can be of practical importance in terms of selectivity. Selectivities of $\mathrm{H}_{2} \mathrm{~S}$ to the non-polar substances were generally higher at lower $\mathrm{H}_{2} \mathrm{~S}$ partial pressures in the bulk gas, and well over 1000 for the range of $\mathrm{H}_{2} \mathrm{~S}$ contents of the typical hydrodesulfurization streams. The obtained order of magnitude of the isosteric heat of adsorption data and the large decrease in selectivity with increasing temperature suggest that electrostatic interactions play a more pronounced role in the selective removal of $\mathrm{H}_{2} \mathrm{~S}$ by zeolite $\mathrm{NaA}$ and the effect of size has only a limited impact. In association with this, it was also revealed that $\mathrm{H}_{2} \mathrm{~S}-\mathrm{H}_{2} \mathrm{~S}$ attraction contributes to the preferred adsorption of this substance.

\section{Acknowledgement}

Present article was published in the frame of the project GINOP-2.3.2-15-2016-00053 ("Development of engine fuels with high hydrogen content in their molecular structures (contribution to sustainable mobility)"). We gratefully acknowledge the financial support of the Hungarian National Research Fund (OTKA K124353). The author would like to thank Tamás Kovács and Zoltán Ható (Department of Physical Chemistry, Institute of Chemistry, University of Pannonia) for their assistance in terms of data analysis.

\section{REFERENCES}

[1] Auerbach, S.M.; Carrado, K.A.; Dutta, P.K. (Eds.): Handbook of Zeolite Science and Technology (Marcel Dekker, New York) 2003 ISBN: 0-8247-4020- 
[2] Xu, X.; Yang, W.; Liu, J.; Chen, X.; Lin, L.; Stroh, N.; Brunner, H.: Synthesis and gas permeation properties of an NaA zeolite membrane, Chem. Commun. 2000 0, 603-604 DOI: 10.1039/B000478M

[3] Aoki, K.; Kusakabe, K.; Morooka, S.: Separation of gases with an A-type zeolite membrane, Ind. Eng. Chem. 2000 39, 2245-2251 DOI: 10.1021/ie990902c

[4] Okamoto, K.; Kita, H.; Horii, K.; Tanaka, K.; Kondo, M.: Zeolite NaA membrane: preparation, single-gas permeation, and pervaporation and vapor permeation of water/organic liquid mixtures, Ind. Eng. Chem. 2001 40, 163-175 DOI: 10.1021/ie0006007

[5] Zhu, W.; Gora, L.; van den Berg, A.W.C.; Kapteijn, F.; Jansen, J.C.; Moulijn, J.A.: Water vapour separation from permanent gases by a zeolite4A membrane, J. Membrane Sci. 2005 253, 57-66 DOI: 10.1016/j.memsci.2004.12.039

[6] Yamamotoa, T.; Kimb, Y.H.; Kimb, B.C.; Endoa, A.; Thongprachana, N.; Ohmoria, T.: Adsorption characteristics of zeolites for dehydration of ethanol: Evaluation of diffusivity of water in porous structure, Chem. Eng. J. 2012 181-2, 443-448 DOI: 10.1016/j.cej.2011.11.110

[7] Lee, S.H.; Moon, G.K.; Choi, S.G.; Kim, H.S.: Molecular dynamics simulation studies of zeoliteA. 3. Structure and dynamics of $\mathrm{Na}^{+}$ions and water molecules in a rigid zeolite-A, J. Phys. Chem. 1994 98, 1561-1569 DOI: 10.1021/j100057a006

[8] Akten, E.D.; Siriwardane, R.; Sholl, D.S.: Monte Carlo Simulation of Single- and Binary Component Adsorption of $\mathrm{CO}_{2}, \mathrm{~N}_{2}$, and $\mathrm{H}_{2}$ in Zeolite $\mathrm{Na}-4 \mathrm{~A}$, Energy \& Fuels 2003 17, 977-983 DOI: 10.1021/ef0300038

[9] Furukawa, S.; Goda, K.; Zhang, Y.; Nitta, T.: Molecular simulation study on adsorption and diffusion behavior of ethanol/water molecules in $\mathrm{NaA}$ zeolite crystal, J. Chem. Eng. Japan 2004 37, $67-$ 74 DOI: $10.1252 /$ jcej. 37.67

[10]Kristóf, T.; Csányi, É.; Rutkai, G.; Merényi, L.: Prediction of adsorption equilibria of watermethanol mixtures in zeolite $\mathrm{NaA}$ by molecular simulation, Mol. Sim. 2006 32, 869-875 DOI: 10.1080/08927020600934179

[11]Cosoli, P.; Ferrone, M.; Pricl, S.; Fermeglia, M.: Hydrogen sulphide removal from biogas by zeolite adsorption, Part I-II, Chem. Eng. J. 2008 145, 8692 and 93-99 DOI: $10.1016 / j . c e j .2008 .07 .034$ \& 10.1016/j.cej.2008.08.013

[12]Rutkai, G.; Csányi, É.; Kristóf, T.: Prediction of adsorption and separation of water-alcohol mixtures with zeolite NaA, Microporous and Mesoporous Mat. 2008 114, 455-464 DOI: 10.1016/j.micromeso.2008.01.044

[13] Csányi, É.; Kristóf, T.; Lendvay, Gy.: Potential model development using quantum chemical information for molecular simulation of adsorption equilibria of water-methanol (ethanol)mixtures in zeolite NaA-4, J. Phys. Chem. C 2009 113, 12225 12235 DOI: $10.1021 /$ jp $902520 \mathrm{p}$
[14]Csányi, É.; Ható, Z.; Kristóf, T.: Molecular simulation of water removal from simple gases with zeolite NaA, J. Mol. Model. 2009 18, 2349-2356 DOI: 10.1007/s00894-011-1253-7

[15] Sun, Y.; Han, S.: Diffusion of $\mathrm{N}_{2}, \mathrm{O}_{2}, \mathrm{H}_{2} \mathrm{~S}$ and $\mathrm{SO}_{2}$ in MFI and 4A zeolites by molecular dynamics simulations, Mol. Sim. 2015 41, 1095-1109 DOI: 10.1080/08927022.2014.945082

[16] Vujic, B.; Lyubartsev, A.P.: Transferable forcefield for modelling of $\mathrm{CO}_{2}, \mathrm{~N}_{2}, \mathrm{O}_{2}$ and $\mathrm{Ar}$ in all silica and $\mathrm{Na}^{+}$exchanged zeolites, Modelling Simul. Mater. Sci. Eng. 2016 24, 045002 (1-26) DOI: 10.1088/0965-0393/24/4/045002

[17]Pluth, J.J.; Smith, J.V.: Accurate redetermination of crystal structure of dehydrated zeolite $\mathrm{A}$. Absence of near zero coordination of sodium. Refinement of $\mathrm{Si}$, Al-ordered superstructure, J. Am. Chem. Soc. 1980 102, 4704-4708 DOI: 10.1021/ja00534a024

[18] Mikula, A.; Król, M.; Kolezynski, A.: Periodic model of an LTA framework, J. Mol. Model. 2015 21, 275 (1-9) DOI 10.1007/s00894-015-2820-0

[19]Bai, P.; Tsapatsis, M.; Siepmann, J.I.: TraPPE-zeo: Transferable Potentials for Phase Equilibria Force Field for All-Silica Zeolites, J. Phys. Chem. C 2013 117, 24375-24387 DOI: 10.1021/jp4074224

[20] Shah, M.S.; Tsapatsis, M.; Siepmann, J.I.: Development of the Transferable Potentials for Phase Equilibria Model for Hydrogen Sulfide, J. Phys. Chem. B 2015 119, 7041-7052 DOI: 10.1021/acs.jpcb.5b02536

[21]Kaminski, G.; Duffy, E.; Matsui, T.; Jorgensen, W.: Free Energies of Hydration and Pure Liquid Properties of Hydrocarbons from the OPLS AllAtom Model, J. Phys. Chem. 1994 98, $13077-$ 13081 DOI: $10.1021 / \mathrm{j} 100100 \mathrm{a} 043$

[22]Darkrim, F.; Levesque, D.: Monte Carlo simulations of hydrogen adsorption in single-walled carbon nanotubes, J. Chem. Phys. 1998 109, 49814984 DOI: 10.1063/1.477109

[23] Waldman, M.; Hagler, A.: New combining rules for rare gas van der Waals parameters, J. Comput. Chem. 1993 14, 1077-1084 DOI: 10.1002/jcc.540140909

[24] Song, W.; Rossky, P.J.; Maroncelli, M.: Modelling alkane+perfluoroalkane interactions using all-atom potentials: Failure of the usual combining rules, $J$. Chem. Phys. 2003 119, 9145-9162 DOI: 10.1063/1.1610435

[25] Gubbins, K.E.; Quirke, N. (Eds.): Molecular Simulation and Industrial Applications: Methods, Examples and Prospects (Gordon \& Breach, Amsterdam) 1997 ISBN: 9056990055, 9789056990053

[26] Wolf, D.; Keblinski, P.; Phillpot, S.R.; Eggebrecht, J.: Exact method for the simulation of Coulombic systems by spherically truncated, pairwise $\mathrm{r}^{-1}$ summation, J. Chem. Phys. 1999 110, 8254-8282 DOI: $10.1063 / 1.478738$

[27]Demontis, P.; Spanu, S.; Suffritti, G.B.: Application of the Wolf method for the evaluation of Coulombic interactions to complex condensed matter systems: Aluminosilicates and water, J. Chem. Phys. 2001 114, 7980-7988 DOI: 10.1063/1.1364638 
[28] Nicholson, D.; Parsonage, N.G.: Computer Simulation and the Statistical Mechanics of Adsorption (Academic Press, London) 1982 ISBN: 0125180608, 9780125180603

[29] Karavias, F.; Myers, A.L.: Isosteric heats of multicomponent adsorption: thermodynamics and computer simulations, Langmuir 1991 7, 3118-3126 DOI: 10.1021/la00060a035

[30] Myers, A.; Prausnitz, J.M.: Thermodynamics of mixed-gas adsorption, AIChE J. 1965 11, 121-127 DOI: $10.1002 /$ aic.690110125

[31] Simon, C.M.; Smit, B.; Haranczyk, M.: pyIAST: Ideal adsorbed solution theory (IAST) Python package, Comp. Phys. Commun. 2016 200, 364380 DOI: $10.1016 /$ j.cpc.2015.11.016

[32] Cruz, A.J.; Pires, J.; Carvalho, A.P.; Carvalho, M.B.: Physical Adsorption of $\mathrm{H}_{2} \mathrm{~S}$ Related to the Conservation of Works of Art: The Role of the Pore Structure at Low Relative Pressure, Adsorption 2005 11, 569-576 DOI: 10.1007/s10450-005-5614-3
[33]Mohr, R.J.; Vorkapic, D.; Rao, M.B.; Sircar, S.: Pure and Binary Gas Adsorption Equilibria and Kinetics of Methane and Nitrogen on 4A Zeolite by Isotope Exchange Technique, Adsorption 1999 5, 145-158 DOI: 10.1023/A:1008917308002

[34] Tant, Z.; Gubbins, K.E.: Selective Adsorption of Simple Mixtures in Slit Pores: A Model of Methane-Ethane Mixtures in Carbon, J. Phys. Chem. 1992 96, 845-854 DOI: 10.1021/j100181a059

[35]Battisti, A.; Taioli, S.; Garberoglio, G.: Zeolitic imidazolate frameworks for separation of binary mixtures of $\mathrm{CO}_{2}, \mathrm{CH}_{4}, \mathrm{~N}_{2}$ and $\mathrm{H}_{2}$ : A computer simulation investigation, Microporous and Mesoporous Mat. 2011 143, 46-53 DOI: 10.1016/j.micromeso.2011.01.029 